Egyptian

Orthodontic Journal

\title{
COMPARATIVE STUDY OF SHEAR BOND STRENGTHS BETWEEN CONVENTIONAL ETCHING AND SELF ETCHING PRIMER
}

\author{
El Sakhawy M.M.* Gaballa S.M.* \\ Ghada A. El-Mehy ${ }^{* * *}$ Abd El Razek R. ${ }^{* * *}$
}

ABSTRACT

This study was designed to compare shear bond strength durability of two etching techniques, conventional etching and self etching primer technique. Ninety extracted premolars was divided into two equal groups (group 1: etched with 35\% Phosphoric acid and group 2: bonded with transbond plus self-etching primer, each group was further subdivided into three subgroups each of them containing fifteen teeth, at different storage time, for 24 hours, 30 days and 3 months. Universal testing machine was used to measure shear bond strength. T-test revealed that there was no significant difference in shear bond strength between the two etching techniques at 24 hours and 30 days, while showed a highly significant difference $(P \leq 0.01)$ at 3 months. For the three storage time, self etching primer showed less adhesive remaining on the teeth than that of Phosphoric acid etching. It could be concluded that self-etching primer provided shear bond strength Comparable to that of phosphoric acid, and less adhesive reminant than conventional etching technique.

\footnotetext{
* Prof. of Orthod. Faculty of Dentistry Tanta Univ.

** Prof. of Orthod. Faculty of Dentistry Tanta Univ.

**** Lecturer of Orthod. Faculty of Dentistry Tanta Univ.

${ }^{* * * *}$ Master student in Orthod. Faculty of Dentistry Tanta Univ.
} 
Egyptian

Orthodontic Journal

\section{INTRODUCTION}

The direct bonding of orthodontic brackets had improved the clinical practice of orthodontics. The acid-etch technique introduced by Buonocore ${ }^{(12)}$ in 1955 involved conditioning the enamel surface with phosphoric acid. Conventional adhesive systems used three different agents in the process of bonding orthodontic bracket to enamel (an enamel etchant, a primer solution, and an adhesive resin).

The use of acidic or self-etching primer is thought to simplify the clinical handling of adhesive systems by combining the etching step with primer application in one mix. Because the monomers that cause the etching are also responsible for bonding, the depth of penetration of the monomers to be polymerized is exactly the same as the depth of demineralization resulting in a complete hybrid layer, as both the etching and priming depth are identical ${ }^{(24)}$.

The introduction of adhesive precoated (APC) brackets offers several advantages over conventional brackets. First: there is consistent quality and quantity of light-cured adhesive on the bracket base, since it is applied by the manufacturer. Second: bracket positioning is more consistent due to both the light-curing method and the consistent quantity of the adhesive. Third: the bonding procedures are faster, since archwires can be placed immediately. Fourth: clean up is easier because of minimal amounts of flash. Material waste is less, with the elimination of mixing pads, syringes, and other dispensers. Fifth: asepsis is improved, since each bracket is packaged separately in blister wrap for light protection ${ }^{(18)}$. The introduction of the new APCII adhesive system facilitated the bonding procedures, as it is lighter, less viscous than the original APC adhesive. It is soft enough to assure accurate placement, yet firm enough to virtually eliminate bracket drift and excessive flash.

The site of bond failure provides information about the quality of the bond between the composite and the tooth, and the composite and the bracket base. There are two main sites; the bracket base / adhesive interface and the enamel / adhesive interface. Cohesive failure occurs within the main bulk of the adhesive material. Ideally in orthodontics, one would like an adequate bond strength which fails at the enamel / composite interface as this would make debonding and subsequent polishing much easier.

\section{The aim of this study was to:}

1- Evaluate the durability of the shear bond strength of the new APCII adhesive system (adhesive precoated brackets) after using two different etching 
techniques; conventional etching technique and etching with self-etching primer.

2- Examine the amount of the adhesive after debonding and its relationship to the technique of etching.

3- Determine which of the etching techniques gave the optimal bond strength.

\section{Materials and Methods:}

This study was carried on ninety extracted maxillary premolars collected from patients seeking for orthodontic treatment in the Department of Orthodontics, Faculty of Dentistry, Tanta University.

The criteria for teeth selection included: intact buccal enamel with no caries or cracks due to the pressure of the extraction forceps and the teeth were not subjected to any chemical agent affecting the enamel (e.g., hydrogen peroxide, formaldehyde). After extraction, the teeth were washed, cleaned from debris, and stored in saline solution until used.

The teeth were divided into two groups according to the etching technique, each group containing forty - five teeth. All the steps were performed according to the manufacture's instructions.

\section{Group I:}

The teeth were etched with $35 \%$ phosphoric acid (Transbond XT Etching Gel) for 15 seconds, washed with a water spray for 15 seconds, and dried with an oil and moisture free air source for 2-3 seconds. The buccal surfaces appeared chalky white in color. A thin coat of Transbond XT primer was applied by a brush to the etched area, thinned with a gentle stream of oil and moisture free air, and light cured for 15 seconds. Upper premolar APCII (adhesive precoated brackets, Gemini, 0.022-inch slot, Roth prescription) were bonded to the teeth.

\section{Group II:}

Transbond Plus Self-Etching Primer was used to etch and prime the teeth at the same time. It is supplied in a lollipop-shaped aluminum foil packet that consists of three separated compartments: one contains methacrylated phosphoric acid esters, initiators, and stabilizers, whereas the other contains water, fluoride complex, and stabilizers. The third compartment had a microbrush applicator to apply the resulting mix into the tooth Fig (1). 
Egyptian

Orthodontic Journal

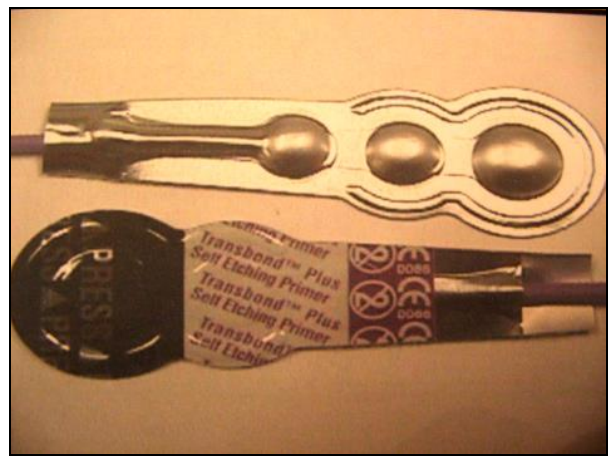

Fig (1): Transbond Plus self- Etching Primer

Each group was subdivided into three subgroups A, B, and C, each of them containing fifteen teeth.

\section{Subgroup A:}

The specimens were stored in distilled water for twenty-four hours.

\section{Subgroup B:}

The specimens were stored in distilled water for thirty days.

\section{Subgroup C:}

The specimens were stored in distilled water for three months.

The distilled water was changed weekly to avoid deterioration ${ }^{(13)}$.

\section{Shear bond strength testing:}

Each specimen was clamped in universal testing machine. A sharpened chisel blade was placed in contact with the incisal aspect of the bracket. An occlusogingival load was applied to the bracket producing a shear force at the bracket /tooth interface using 500 newtons load cell with a crosshead speed of 2 $\mathrm{mm} /$ minute $^{(34)}$. A computer electronically connected to the testing machine recorded the result of each test. For each specimen, the debonding force was recorded in newtons and divided by the base surface area of the bracket to obtain the shear bond strength in megapascal (MPa).The base surface area of the bracket was $10.5 \mathrm{~mm}^{2}$, as reported by the manufacturer (Fig 2). 


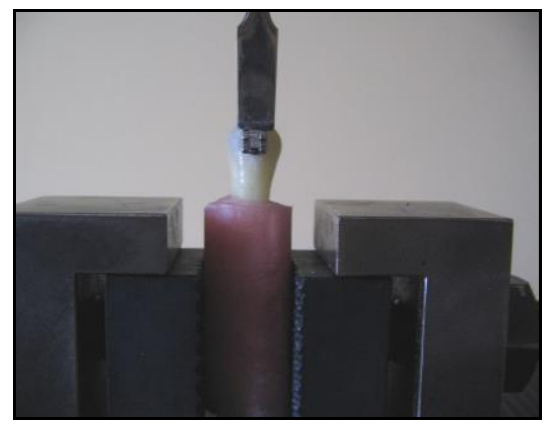

Fig (2): Shear bond strength testing

\section{Evaluation of the residual adhesive:}

After bond failure, the bracket base and the enamel surface were examined under 10X magnification. The amount of adhesive remaining on the teeth surface was assessed with the adhesive remnant index (ARI) as described by Artun and Bergland (1984) $)^{(3)}$ as follows:

- Score $\mathbf{0}=$ no adhesive left on the tooth surface.

- Score 1 = less than half of the adhesive left on the tooth surface.

- Score 2 = more than half of the adhesive left on the tooth surface.

- Score 3 = all the adhesive left on the tooth surface, with a distinct impression of the bracket base.

Statistical analysis was carried out using SAS program (SAS, 1988). Student $t$ test (Procedure TTEST of SAS) was run to compare the effect of etching techniques within each time. Chi-square test (Procedure Freq of SAS) was used to compare the prevalence of ARI scores between times within each etching technique as well as between etching techniques within each time.

\section{RESULTS}

The results of this study revealed that there was no significant difference in shear bond strength between the two etching techniques at 24 hours and 30 days, while showed a highly significant difference $(\mathrm{P} \leq 0.01)$ at three months (phosphoric acid group was higher than self-etching primer group, 18.27Mpa., 12.5 Mpa., respectively) (Table (1) \& Figure (3)).

Concerning ARI scores, The chi-square test showed that, at 24 hours, there was a significance difference $(\mathrm{P} \leq 0.05)$ in ARI scores between phosphoric acid etching and self-etching primer. 
At 30 days, there was a highly significant difference $(P \leq 0.01)$ in ARI score between the two etching techniques. At 3 months there was a significant difference $(\mathrm{P} \leq 0.05)$ in ARI scores between the two groups.

For the three storage time, self-etching primer showed less adhesive remaining on the teeth than that of phosphoric acid etching (Table (2) \& Figure (4))

Table (1): Descriptive statistics and test of significance (Student $t$ test) for the effect of etching on shear bond strength at different times.

\begin{tabular}{|l|c|c|c|c|c|}
\hline \multicolumn{1}{|c|}{ Etching technique } & \multicolumn{2}{|c|}{ phosphoric acid } & \multicolumn{2}{c|}{ self etching primer } & \\
\hline Time & Mean & S.D. & Mean & S.D. & p \\
\hline $24 \mathrm{hrs}$ & 14.581 & \pm 4.945 & 12.679 & \pm 3.128 & NS \\
\hline 30 days & 15.299 & \pm 4.407 & 15.171 & \pm 3.431 & NS \\
\hline 3 months & 18.268 & \pm 4.597 & 12.500 & \pm 5.332 & $* *$ \\
\hline
\end{tabular}

S.D. $=$ Standard deviation

$\mathrm{P} \quad=$ Probability level.

$\mathrm{NS}=$ Non significant $(\mathrm{p}>0.05) . \quad * *=$ Significant at $\mathrm{P} \leq 0.01$

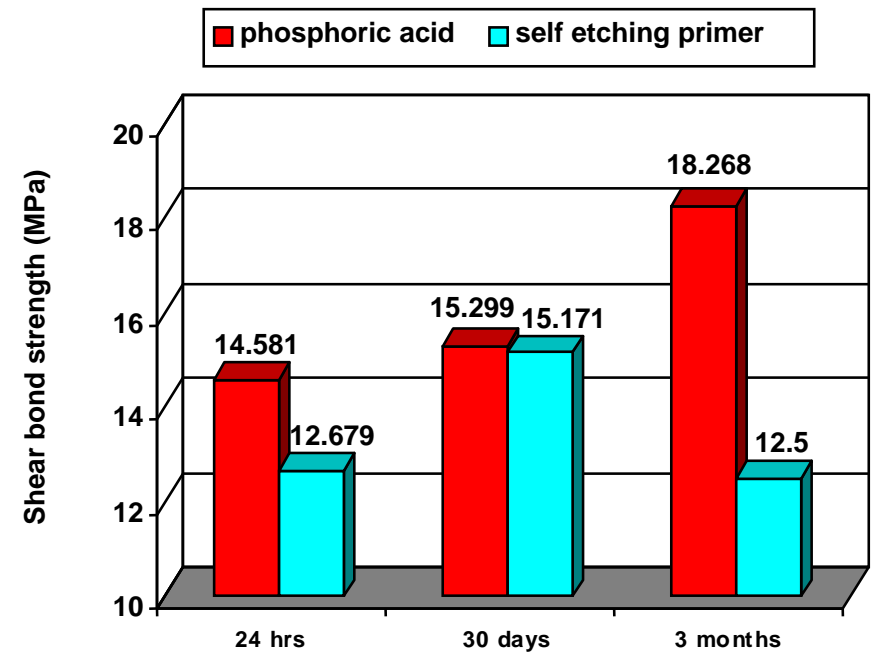

Fig (3): Mean shear bond strengths of the two etching techniques at different times. 


\section{Egyptian}

Orthodontic Journal

Table (2): Cross tabulation and Chi square test of significance for the effect of etching on the prevalence of ARI scores at different times.

\begin{tabular}{|c|c|c|c|c|c|c|}
\hline & \multirow{2}{*}{$\begin{array}{c}\text { Etching } \\
\text { Score }\end{array}$} & \multicolumn{2}{|c|}{ Phosphoric acid } & \multicolumn{2}{|c|}{ Self etching primer } & \\
\hline & & No & $\%$ & No & $\%$ & $\mathbf{p}$ \\
\hline \multirow{5}{*}{ 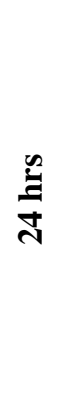 } & 0 & 1 & 6.7 & 4 & 26.7 & \multirow{5}{*}{$*$} \\
\hline & 1 & 3 & 20.0 & 8 & 53.3 & \\
\hline & 2 & 4 & 26.7 & 0 & 0.0 & \\
\hline & 3 & 7 & 46.7 & 3 & 20.0 & \\
\hline & Total & 15 & 100 & 15 & 100 & \\
\hline \multirow{5}{*}{ 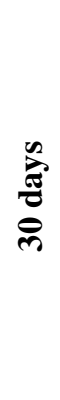 } & 0 & 6 & 40.0 & 14 & 93.3 & \multirow{5}{*}{$* *$} \\
\hline & 1 & 5 & 33.3 & 1 & 6.7 & \\
\hline & 2 & 0 & 0.0 & 0 & 0.0 & \\
\hline & 3 & 4 & 26.7 & 0 & 0.0 & \\
\hline & Total & 15 & 100 & 15 & 100 & \\
\hline \multirow{5}{*}{ 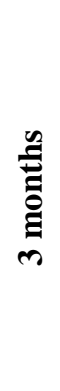 } & 0 & 6 & 40.0 & 1 & 6.7 & \multirow{5}{*}{$*$} \\
\hline & 1 & 3 & 20.0 & 12 & 80.0 & \\
\hline & 2 & 2 & 13.3 & 1 & 6.7 & \\
\hline & 3 & 4 & 26.7 & 1 & 6.7 & \\
\hline & Total & 15 & 100 & 15 & 100 & \\
\hline
\end{tabular}

$\mathrm{P}=$ Probability level.

* $=$ Significant at $\mathrm{P} \leq 0.05$

NS $=$ Nonsignificant $(\mathrm{p}>0.05)$.

$* *=$ Significant at $\mathrm{P} \leq 0.01$ 
$\square 0 \square 1 \square 2 \square 3$

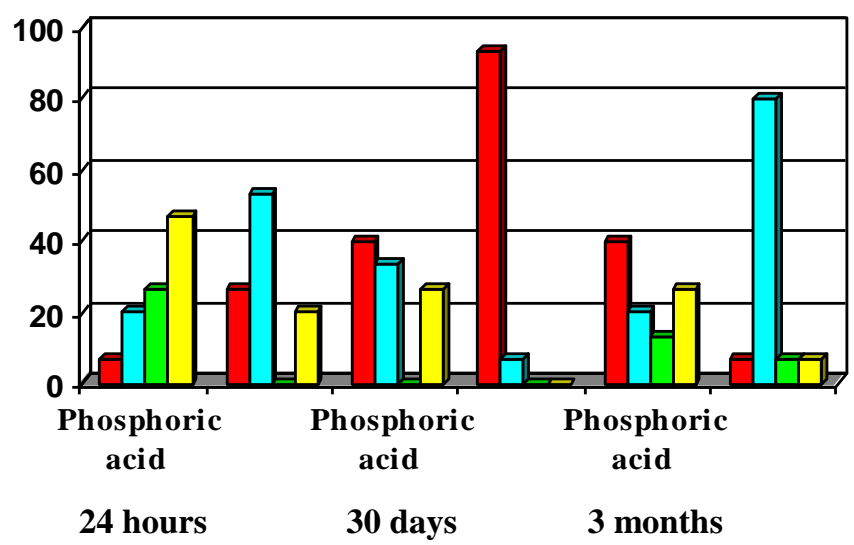

Fig (4): Prevalence of ARI scores using phosphoric acid and self etching primer techniques at different times.

\section{DISCUSSION}

Reynolds ${ }^{(28)}$ suggested that shear bond strengths of metal orthodontic brackets to enamel should range from 6 to $8 \mathrm{MPa}$ for clinically adequate bond strength. The study showed that all shear bond strengths were above that limit in both etching techniques which suggested that self-etching primers can be successfully used for bonding orthodontic brackets to enamel. These results were in agreement with other studies ${ }^{(2,6,8,10,11,13,14,15)}$ which suggested that adequate shear bond strengths can be achieved with self-etching primers. So both etching techniques gave optimal bond strength.

For phosphoric acid etching, the test showed no significant difference in shear bond strength between 24 hours and 30 days values. These results were agreed with McCourt et al., ${ }^{(22)}$,Nagel ${ }^{(26)}$ and Lippitiz et al., ${ }^{(21)}$. The obtained data revealed an increase in shear bond strength from 30 days to 3 months which was supported by Trites et al., ${ }^{(34)}$.On the other hand, the results contradicted with Murray and Hobson ${ }^{(25)}$. The results revealed a significant difference in shear bond strength between 24 hours and 3 months. On the basis of this study, this increase in shear bond strength from 24 hours to 3 months associated with the use of phosphoric acid etching may be explained by further polymerization of the deep resin tags of the adhesive material that created after infiltration of the resin material into the demineralized surfaces produced by phosphoric acid 
etching. This finding was supported by Cal-Neto and Miguel ${ }^{(16)}$ who concluded that phosphoric acid etching produced deeper etching pattern and deeper resin tags than that of self-etching primers which formed more conservative shallower etching pattern and shorter resin tags.

For Transbond Plus Self-Etching Primer, the results of this study showed that the shear bond strength increased from 24 hours to 30 days and then decreased from 30 days to 3 months, however these changes were not significant in relation to time. The decrease in shear bond strength when self-etching primer was used, was in agreement with the results of Sadr et al., ${ }^{(31)}$ who reported a significant decrease in shear bond strength of Clearfil Tri-S Bond (TS) at 4 weeks and significant decrease in shear bond strength of Clearfil SE Bond (SE) at 16 weeks (4 months).

One of the aims of this study was to evaluate the site of bond failure after debonding and its relationship to the technique of etching. When phosphoric acid was used for etching, the results revealed significant difference $(p \leq 0.05)$ in ARI scores between 24 hours and 30 days. At 24 hours, the pattern of bond failure was mostly cohesive and at the bracket / adhesive interface while at 30 days it was mixed mode of failure. After 24 hours, the results were agreed with Buyukyilmaz et al., ${ }^{(13)}$, Bearn et al., ${ }^{(4)}$, Sfondrini et al., ${ }^{(32)}$ Bishara et al., ${ }^{(9)}$ and $\mathrm{Al}$ Shamsi ${ }^{(1)}$.The results disagreed with Sunna and Rock ${ }^{(33)}$.

After 30 days, The data were in agreement with Cal-Neto et al., ${ }^{(15)}$. On the other hand, these finding contradicted with Lalani et al., ${ }^{(20)}$, Rix et al., ${ }^{(29)}$ Cehreli et al., ${ }^{(17)}$ and Meehan et al., ${ }^{(23)}$.At 3 months, the mode of bond failure was also mixed. These results disagreed with Trites et al., ${ }^{(34)}$. Variation in bond failure mode from other studies may be explained by O'Brien et al., ${ }^{(27)}$ who suggested that ARI scores depended on many factors which included the bracket base design, adhesive type and the bond strengths at the separate interfaces.

The obtained data revealed cohesive bond failure at 24 hours storage when Transbond Plus Self-Etching Primer was used. This finding was supported by Trites et al., ${ }^{(34)}$ and Buyukyilmaz et al., ${ }^{(13)}$ while contradicted with those of Romano et al., ${ }^{(30)}$.

After 30 days, the results showed failure at the enamel / adhesive interface. This finding agreed with Cehreli et al., ${ }^{(17)}$ and Fox et al., ${ }^{(19)}$. On the other hand, these data were disagreed with Trites et al., ${ }^{(34)} \&$ Cal-Neto et al., ${ }^{(15)}$.

After 3 months, the obtained data revealed cohesive bond failure which agreed with Trites et al., ${ }^{(34)}$ who used the same self-etching primer with Transbond XT adhesive. 
Egyptian

Orthodontic Journal

\section{CONCLUSIONS}

1. Transbond plus Self-etching primer can be successfully used for bonding orthodontic brackets as it provided shear bond strength comparable to that of phosphoric acid.

2. The shear bond strength of phosphoric acid increased significantly with time while that of transbond plus self etching primer showed no significant change as time passed.

3. Transbond plus self etching primer showed less adhesive remaining on the teeth than that of phosphoric acid etching.

\section{RECOMMENDATION}

Long-term clinical evaluations are still required to confirm the superiority of the Self-Etch approach for bonding orthodontic brackets.

\section{REFERENCES}

1- Al shamsi A, Cunningham JL, Lamey PJ, Lynch E: Shear bond strength and residual adhesive after orthodontic bracket debonding. Angle Orthod. 2006; 76: $694-699$.

2- Arnold RW, Combe EC, Warford JH Jr: Bonding of stainless steel brackets to enamel with a new self-etch primer. Am J Orthod Dentofacial Orthop. 2002; 122: 274-276.

3- Årtun J, Bergland S: Clinical trials with crystal growth conditioning as an alternative to acid-etch enamel pretreatment. Am J Orthod. 1984; 85: 333-340.

4- Bearn DR, Aird JC, McCabe JF: Ex vivo bond strength of adhesive precoated metallic and ceramic brackets. Br J Orthod. 1995; 22(3): 233-236.

5- Bishara SE, Ajlouni R, Laffoon JF, Warren JJ: Comparison of shear bond strength of two self-etch primer/ adhesive systems. Angle Orthod. 2006; 76:123 - 126.

6- Bishara SE, Ajlouni R, Laffoon JF, Warren JJ: Effect of a fluoride-releasing self-etch acidic primer on the shear bond strength of orthodontic brackets. Angle Orthod. 2002; 72: 199-202.

7- Bishara SE, Ajlouni R, Laffoon JF, Warren JJ: Effects of modifying the adhesive composition on the bond strength of orthodontic brackets. Angle Orthod. 2002; 72:464-467. 
8- Bishara SE, Gordan VV, VonWald L, Olson ME: Effect of an acidic primer on shear bond strength of orthodontic brackets. Am J Orthod Dentofacial Orthop. 1998; 114: 243-247.

9- Bishara SE, Olsen ME, Von Wald L: Comparisons of shear bond strength of precoated and uncoated brackets. Am J Orthod Dentofacial Orthop. 1997; 112: 617-621.

10- Bishara SE, Oonsombat C, Ajlouni R, Laffoon JF: Comparison of the shear bond strength of 2 self-etch primer / adhesive systems. Am J Orthod Dentofacial Orthop. 2004; 125: 348-350.

11- Bishara SE, VonWald L, Laffoon JF, and Warren JJ: Effect of a self-etch primer/adhesive on the shear bond strength of orthodontic brackets. Am J Orthod Dentofacial Orthop. 2001; 119: 621-624.

12- Buonocore MG: A simple method of increasing the adhesion of acrylic filling materials to enamel surfaces. J Dent Res. 1955; 34: 849 - 853.

13- Buyukyilmaz T, Usumez S, and Karaman AI: Effect of self-etching primers on bond strength — are they reliable?. Angle Orthod. 2003; 73: 64-70.

14- Cal-Neto JP, Carvalho F, Almeida RCC, Miguel JAM: Evaluation of a new self-etching primer on bracket bond strength in vitro. Angle Orthod. 2006; 76: $466-469$.

15- Cal-Neto JP, Miguel JAM, Zanella E: Effect of a self-etching primer on shear bond strength of adhesive precoated brackets bonded in vivo. Angle Orthod. 2006; 76: 127 - 131 .

16- Cal-Neto JP, Miguel JAM: Scanning electron microscopy evaluation of the bonding mechanism of a self-etching primer on enamel. Angle Orthod. 2006; 76: 132 - 136 .

17- Cehreli ZC, Kecik D, Kocadereli I: Effect of self-etching primer and adhesive formulations on the shear bond strength of orthodontic brackets. Am J Orthod Dentofacial Orthop. 2005; 127: 573-579.

18- Cooper RB, Goss M, Hamula W: Direct bonding with light cured adhesive precoated brackets. J Clin Orthod. 1992; 26: 477-479.

19- Fox NA, McCabe JF, Buckley JG: A critique of bond strength testing in orthodontics. Br J Orthod. 1994; 21: 33 - 43.

20- Lalani N, Foley TF, Voth R, Banting D, Mamandras A: Polymerization with the argon laser: curing time and shear bond strength. Angle Orthod. 2000; 70: 28-33. 
21- Lippitz SJ, Staley RN, Jakobsen JR: In vitro study of 24-hour and 30-day shear bond strengths of three resin-glass ionomer cements used to bond orthodontic brackets. Am J Orthod Dentofacial Orthop. 1998; 113: 620 - 624.

22- McCourt JW, Cooley RL, Barnwell S: Bond strength of light cure fluoridereleasing base-liners as orthodontic bracket adhesives. Am J Orthod Dentofacial Orthop. 1991; 100(1): 47-52.

23- Meehan MP, Foley TF, Mamandras AH: A comparison of the shear bond strengths of two glass ionomer cements. Am J Orthod Dentofacial Orthop. 1999; 115: 125 - 132.

24- Miller RA: Laboratory and clinical evaluation of a self-etching primer. J Clin Orthod. 2001; 35: $42-45$.

25- Murray SD, Hobson RS: Comparison of in vivo and in vitro shear bond strength. Am J Orthod Dentofacial Orthop. 2003; 123: 2 - 9.

26- Nagel NJ: A materials evaluation of ten direct bonding systems utilizing polycarbonate bracket. Am J Orthod. 1975; 67: 460 - 461.

27- O'Brien KD, Watts DC, Read MJ: Residual debris and bond strength-is there a relationship? Am J Orthod Dentofacial Orthop. 1988; 94(3):222-230.

28- Reynolds I: A review of direct orthodontic bonding. Br J Orthod. 1975; 2 : 171-178.

29- Rix D, Foley TF, Mamandras A: Comparison of bond strength of three adhesives: composite resin, hybrid GIC, and glass-filled GIC. Am J Orthod Dentofacial Orthop. 2001; 119: 36 - 42.

30- Romano FL,Tavares SW,Nouer DF,Consani S, and Magnani MBB: Shear bond strength of metallic orthodontic brackets bonded to enamel prepared with self-etching primer. Angle Orthod. 2005; 75: 695 - 699.

31- Sadr A, Ghasemi A, Shimada Y, Tagami J: Effects of storage time and temperature on the properties of two self-etching systems. J Dent. 2006.

32- Sfondrini MF, Cacciafesta V, Klersy C: Halogen versus high-intensity lightcuring of uncoated and pre-coated brackets: a shear bond strength study. J Orthod. 2002; 29: 45-50.

33- Sunna S, Rock WP: An ex-vivo investigation into the bond strength of orthodontic brackets and adhesive systems. Br J Orthod. 1999; 26: 47-50.

34- Trites B, Foley TF, Banting D: Bond strength comparison of two self-etching primers over a three-month storage period. Am J Orthod Dentofacial Orthop. 2004; 12. 